\title{
EFFECT OF NANOCHITOZAN AND NANOPROPOLIS ON MICROTENSILE BOND STRENGTH OF UNIVERSAL ADHESIVE TO DENTIN
}

\author{
Mai Mamdouh Akha* and Rasha Hassan Afifi**
}

\begin{abstract}
Objective: The aim of this in vitro study was to investigate the effect of nanopropolis and nanochitozan on the microtensile bond strength ( $\mu$ TBS) of universal adhesive to dentin.

Materials and methods: Fifteen extracted sound human permanent molars were selected. Occlusal one-third of the tooth crowns was removed to expose the mid-coronal dentin. The teeth were randomly divided into three equal groups according to the pretreatment before application of the adhesive i.e. Group A: $1 \%$ nanochitozan was applied, group B: 1\% nanopropolis was applied and group C: received no treatment (control). Universal adhesive Prime \& Bond ${ }^{\mathrm{TM}}$ was applied in the self- etch mode according to manufacturer's instructions. Composite build-ups were done using a specially fabricated split Teflon mold. After being kept in an incubator at $37^{\circ} \mathrm{C}$ for 24 hours, Teeth were sectioned to obtain beams with cross-sectional areas of about $1 \mathrm{~mm} \times 1 \mathrm{~mm}$. $\mu$ TBS test was done using universal testing machine. One-way ANOVA followed by Tukey post hoc test were used to compare between more than two groups in non-related samples.
\end{abstract}

Results: A statistically significant difference was found between (Group B) and each of (Group A) and (Group C) where $(p=0.001)$. No statistically significant difference was found between (Group A) and (Group C) where $(p=0.115)$.

Conclusion: Within the limitations of this study it could be concluded that, nanopropolis (conc $1 \%$ ) enhance the immediate $\mu$ TBS of Prime $\&$ Bond $^{\mathrm{TM}}$ universal adhesive to dentin. Nanochitozan (conc $1 \%$ ) did not improve the $\mu$ TBS of Prime \& Bond ${ }^{\mathrm{TM}}$ universal adhesive to dentin.

KEYWORDS: Nanochitozan, nanopropolis, dentine, microtensile, universal adhesive.

* Lecturer of Conservative Dentistry, Faculty of Dentistry, Cairo University Egypt.

** Lecturer of Conservative Dentistry, Faculty of Dentistry, Future University in Egypt. 


\section{INTRODUCTION}

The stability of the hybrid layer is a very important factor which affects longevity of resin composite restoration. ${ }^{1}$ However, the methacrylate polymers in adhesive systems may be affected by chemical hydrolysis and enzymatic degradation of the metalloproteinases. ${ }^{2}$ Suppressing the metalloproteinases (MMP) action and preventing the hybrid layer degradation requires the use of cavity pretreatments, adhesive systems resistant to the action of esterases, or collagenolytic enzyme inhibitors. ${ }^{3}$

Chitosan is a natural biopolymer isolated from shellfish, crab and shrimp. It is mostly used due to its biodegradable, nontoxic, non-antigenic, and biocompatible properties. It exhibits many beneficial effects, including strong antimicrobial ${ }^{4}$ and antioxidative activities in food. ${ }^{5}$ The incorporation of the natural biopolymer chitosan in experimental adhesive systems associated with methacrylate monomers has been suggested as a method to enhance the biological and mechanical properties of collagen construction. It can form a microfibrillar and nanofibrillar network with superior mechanical properties and it can also improve antibacterial activity by ionic interactions between chitosan and the bacterial cells. ${ }^{6}$

Propolis is a hive resinous substance processed and collected by honeybees from plant products. It contains more than 150 types of chemicals (such as coumarins, flavonoids, polyphenols, phenolic aldehydes, amino acids and steroids). ${ }^{6}$ It has known to possess many valuable applications as antimicrobial, antiviral, fungicidal, local anestletic, antiulser, antioxidant and in food preservation. ${ }^{7}$ It was suggested that ethyl extract of propolis may has a strong inhibitory effect on the activity of MMP9 due to presence of caffeic acid and phenyl ester. ${ }^{8}$

Nanotechnology has been applied to dentistry as a recent concept for the development of materials and treatment strategies. Nano-scale structures, such as nanoparticles, have a high surface-to-volume ratio which extremely increases the reactivity of these materials because the number of atoms or molecules in the sample mass would be very high. ${ }^{9}$ Accordingly, nanoparticles of bioactive polymers such as chitosan and propolis are expected to be more effective in enhancement of the mechanical properties of dentin collagen and improvement of bond strength. Thus, this study was done to investigate the effect of nanochitozan and nanopropolis on the bond strength of universal adhesive to dentin.

\section{MATERIALS AND METHODS}

Materials used in this study, their compositions, manufacturers and batch numbers are listed in (table 1).

\section{Study design:}

Fifteen extracted sound human permanent molars were selected for the study. They were divided into three groups according to the pretreatment before the application of the adhesive i.e

Group A: $1 \%$ nanochitozan was applied, group B: $1 \%$ nanopropolis was applied, group C: received no treatment (control). Each group was then prepared for microtensile bond strength test. Only the three central beams from every tooth were selected for testing $(\mathrm{N}=15)$.

\section{Nano-chitosan and nano-propolis preparation}

Nanochitosan concentration of $1.0 \%$ was prepared by adding the equal amount (w/v 1:100) of acetic acid to chitosan. Medium molecular chitosan solution at a concentration of $0.05 \%(\mathrm{w} / \mathrm{v})$ was dissolved in glacial acetic acid $(1 \% \mathrm{v} / \mathrm{v})$ and distilled water. $2.5 \mathrm{ml}$ of this chitosan solution was dissolved in methanol $(40 \mathrm{ml})$ by using a peristaltic pump (Bio-Rad, EP-1 Econo Pump) under moderate stirring. The obtained solution was placed in a rotary evaporator (Rotary Evaporator RE 300, BM 500 Water Bath, Yamato CF 300) at $40^{\circ} \mathrm{C}$ and $50 \mathrm{rpm}$.

For the preparation of $1 \%$ propolis nanosolution, a liquid extract of propolis $30 \%$ was dissolved in methanol $(40 \%)$ to obtain a final concentration of $0.6 \%$. The similar methodology used for chitosan nanoparticles preparation was followed. ${ }^{10}$ 
TABLE (1): Materials used in this study, their compositions, manufacturers and batch numbers:

\begin{tabular}{|l|l|l|}
\hline Material & Composition & Manufacturer and batch number \\
\hline \multirow{3}{*}{ Prime \& Bond ${ }^{\mathrm{TM}}$ universal } & $\begin{array}{l}\text { Phosphoric acid modified acrylate resin, Bi-and } \\
\text { Multifunctional acrylate, Acidic monomers (PENTA } \\
\text { \& MDP), Isopropanol, Water, Initiator, Stabilizer, } \\
\text { crosslinking (N-ally), PH>2.5 }\end{array}$ & $\begin{array}{l}\text { Dentsply, DeTrey GmbH, Germany. } \\
\text { Lot number 1811000038 }\end{array}$ \\
\hline Tetric Evoceram bulk fill, & $\begin{array}{l}\text { Urethane dimethacrylate, Bisphenol A dimethacrylate, } \\
\text { Barium glass fillers, ytterbium trifluoride, mixed oxide } \\
\text { prepolymer (79-81 wt\%, 60-61 vol\%) }\end{array}$ & $\begin{array}{l}\text { Ivoclar Vivadent, Schaan, } \\
\text { Liechtenstein } \\
\text { Not v48869. }\end{array}$ \\
\hline $\begin{array}{l}1 \% \text { nanochitosan prepared by adding the equal amount } \\
\text { (w/v 1:100) of acetic acid to chitosan. 0.05\% (w/v) was } \\
\text { dissolved in glacial acetic acid (1\% v/v) and distilled } \\
\text { water 2.5 ml of this chitosan solution was dissolved in } \\
\text { methanol (40 ml) }\end{array}$ & $\begin{array}{l}\text { Nanogate pharmaceutical company, } \\
\text { Cairo, Egypt. }\end{array}$ \\
\hline Nanopropolis & $\begin{array}{l}1 \% \text { propolis nanosolution, a liquid extract of propolis } \\
30 \% \text { was dissolved in methanol (40\%). }\end{array}$ & $\begin{array}{l}\text { Nanogate pharmaceutical company, } \\
\text { Cairo, Egypt. }\end{array}$ \\
\hline
\end{tabular}

\section{Specimen preparation}

Fifteen extracted sound human permanent molars were selected for the study. The extracted teeth were stored in $0.1 \%(\mathrm{w} / \mathrm{v})$ thymol immediately after extraction at room temperature for no more than 1 month. The roots of the teeth were cut $2 \mathrm{~mm}$ below cemento-enamel junction (CEJ) using double sided diamond disc (Edental Golden S.A.W, Switzerland) mounted to a water-cooled low speed cutting handpiece (W\&H, WA-66A, Dentalwerk, Austria). The contents of the pulp chamber were then removed with a broach. Occlusal enamel was removed by wet grinding using a 240 -grit silicon carbide ( $\mathrm{SiC}$ ) abrasive paper mounted in a bench grinder machine to expose midcoronal dentin. Checking the remaining dentin thickness was done using precise caliper. Only specimens of remaining dentin thickness $2 \mathrm{~mm}$ were used in the current study. The dentin surface was polished using a 600grit silicon carbide paper to create a standardized smear layer. The teeth were randomly divided into three groups; five molars in each group.

\section{Nano-agents application}

Five molars were randomly assigned to group A (nanochitosan) where the dentin surfaces were coated with the nanochitosan solution using a microbrush with rubbing for one minute. And the same was done for the other five molars assigned for group B using the nanopropolis solution. Excess solution was removed by absorbent paper before applying the adhesive.

\section{Adhesive procedures}

The universal adhesive Prime \& Bond ${ }^{\mathrm{TM}}$ was then used in the self- etch mode according to the manufacturer's instructions. The adhesive was applied to the pretreated dentin surfaces for a total of $20 \mathrm{~s}$ and then gently air dried for $5 \mathrm{~s}$ and light cured (Blue phase LED light-curing unit, Monitex GT 1200, Taiwan) for $10 \mathrm{~s}$. Composite build-ups were done using the Tetric Evo ceram bulk fill composite (Ivoclar Vivadent, Schaan, Liechtenstein) in $4 \mathrm{~mm}$ bulk with the aid a specially fabricated split Teflon 
mold $(4 \mathrm{mmx} 4 \mathrm{~mm})$. The power intenisty of the light curing unit was checked after curing every 5 specimens using a radiometer (Demetron/Kerr, Danbury, USA).

\section{Micro-rods preparation}

After being kept in an incubator at $37^{\circ} \mathrm{C}$ for 24 hours, the teeth were fixed onto acrylic plates with sticky wax to be sectioned. Teeth were then sectioned across the adhesive interface to obtain forty-five resin-dentin beams; fifteen in each group with cross-sectional areas of about $1 \mathrm{~mm} \times 1 \mathrm{~mm}$ with the IsoMet saw (low speed Isomet 1000, Buehler, Lake Bluff, IL, USA). A digital caliper was used to measure the dimensions of each stick. Only the three central beams from every tooth were selected for testing. The pretest failed specimen were repeated in every group.

\section{Microtensile bond strength test}

Each resin-dentin beam was attached to the testing apparatus with a cyanoacrylate adhesive and loaded until failure under tension using universal testing machine (DL 200MF, Emic Instron, Brazil) at a cross-head speed of $0.5 \mathrm{~mm} / \mathrm{min}$. The microtensile bond strength $\mu$ TBS was calculated as the maximum load at failure divided by the crosssectional area and was expressed in MPa.

\section{Statistical analysis}

The mean and standard deviation values were calculated for each group in each test. Data were explored for normality using Kolmogorov-Smirnov and Shapiro-Wilk tests, data showed parametric (normal) distribution while failure data showed non-parametric (not-normal) distribution. For parametric data, One-way ANOVA followed by Tukey post hoc test was used to compare between more than two groups in non-related samples. For non-parametric data, Kruskal Wallis test was used to compare between more than two groups in nonrelated samples. Mann Whitney test was used to compare between two groups in non-related samples. The significance level was set at $\mathrm{P} \leq 0.05$. Statistical analysis was performed with IBM ${ }^{\circledR}$ SPSS ${ }^{\circledR}$ Statistics Version 20 for Windows (SPSS, Chicago, IL, USA).

\section{RESULTS}

The microtensile bond strength results after treatment with nanopropolis and nanochitozan were presented in table (2), figure (1). It was revealed that, there was a statistically significant difference between (Group A), (Group B) and (Group C) where $(p<0.001)$. A statistically significant difference was found between (Group B) and each of (Group A) and (Group C) where $(p=0.001)$. No statistically significant difference was found between (Group A) and (Group C) where $(p=0.115)$. The highest mean value was found in (Group B) followed by (Group A), while the least mean value was found in (Group $\mathrm{C}$ ).

The pretest failures were presented in table (3), figure (2), there was no statistically significant difference between (Group A), (Group B) and (Group C) where $(p=0.900)$. (Group A) showed 10 $(66.7 \%)$ cases success and $5(33.3 \%)$ cases failed, while (Group B) showed 11 (73.3\%) cases success and $4(26.7 \%)$ cases failed, (Group C) showed 11 $(73.3 \%)$ cases success and $4(26.7 \%)$ cases failed.

TABLE (2) The mean, standard deviation (SD) values of microtensile bond strength of different groups.

\begin{tabular}{|c|c|c|}
\hline \multirow{2}{*}{ Variables } & \multicolumn{2}{|c|}{ Microtensile bond strength } \\
\cline { 2 - 3 } & Mean & SD \\
\hline Group A & $34.80^{\mathrm{b}}$ & 2.48 \\
\hline Group B & $38.00^{\mathrm{a}}$ & 2.33 \\
\hline Group C & $33.13^{\mathrm{b}}$ & 1.85 \\
\hline p-value & \multicolumn{2}{|c|}{$<0.001^{*}$} \\
\hline
\end{tabular}

Means with different small letters in the same column indicate statistically significance difference. *; significant $(p<0.05) \quad n s ;$ non-significant $(p>0.05)$. 


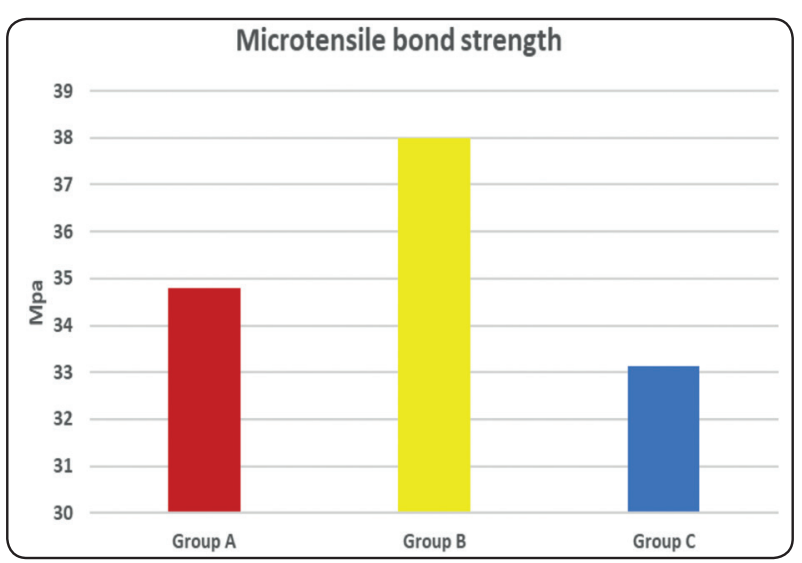

Fig. (1): Bar chart representing microtensile bond strength for different groups.

TABLE (3): The mean, standard deviation (SD) values of failure cases of different groups.

\begin{tabular}{|c|c|c|c|}
\hline \multirow{2}{*}{} & \multicolumn{2}{c|}{ Failure } \\
\cline { 3 - 4 } & \multirow{2}{*}{ Variables } & n & $\%$ \\
\hline \multirow{2}{*}{ Group A } & Failure & 5 & $33.3 \%$ \\
\cline { 2 - 4 } & Success & 10 & $66.7 \%$ \\
\hline \multirow{2}{*}{ Group B } & Failure & 4 & $26.7 \%$ \\
\cline { 2 - 4 } & Success & 11 & $73.3 \%$ \\
\hline \multirow{2}{*}{ Group C } & Failure & 4 & $26.7 \%$ \\
\cline { 2 - 4 } & Success & 11 & $73.3 \%$ \\
\hline \multicolumn{2}{|c|}{$p$-value } & \multicolumn{2}{c}{$\mathbf{0 . 9 0 0 n s}$} \\
\hline
\end{tabular}

ns; non-significant $(\mathrm{p}>0.05)$

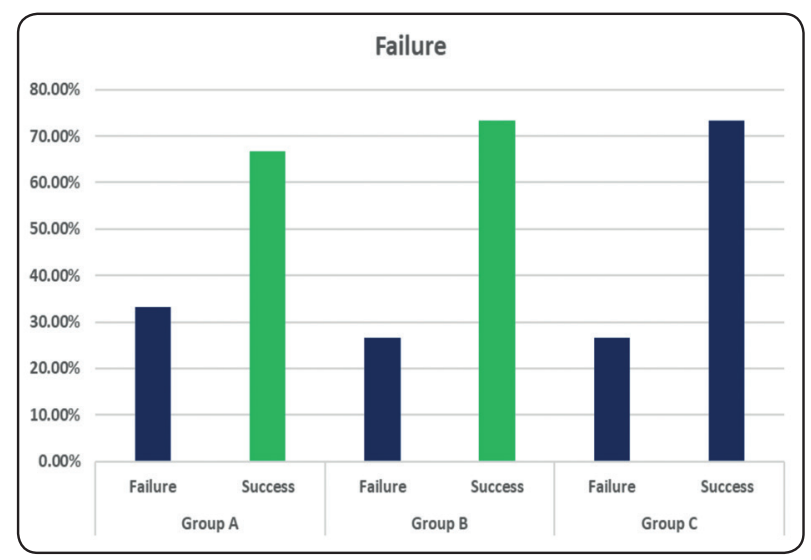

Fig. (2): Bar chart representing failure for different groups.

\section{DISCUSSION}

Nanoparticles were suggested to be integrated in adhesives due to their antibacterial characteristics and to improve the mechanical properties of the adhesives. ${ }^{11}$ Another way to improve durability of resin dentin interface is inhibition of MMPs action and collagen degradation in which MMP inhibitors have been used as a separate dentin preconditioning step. ${ }^{12}$ That is why we apply two nanomaterials suggested to have MMPS inhibition properties as a pretreatment before application of the adhesive in this study.

In this study, propolis were chosen because in addition to its antibacterial and antioxidant activities $^{13}$, propolis is a non-toxic material. It is a biocompatible natural substance that can be used in the oral products safely. ${ }^{14}$ Chitosan is also a biocompatible antibacterial material that can be used in many areas and it has the advantage of being obtained from renewable sources. ${ }^{15,16}$ it shows antioxidant activity by transforming different components into stable molecules through neutralization of free radicals and binding to metal ions. Hydroxyl (-OH) and amino (-NH) groups are the basic groups responsible for this antioxidant activity $^{15}$.

The results of this study revealed that, nanopropolis group showed statistically significant higher microtensile bond strength mean values than nanochitozan. This may be due to flavonoids and phenolic acid contents of propolis which have been shown to have antibacterial, antiviral, and antifungal effects $^{7,17}$, also antioxidant activities ${ }^{13}$. Flavonoid is a major contributing factor in biological activity of the propolis. The biological effects of flavonoids can be subdivided into 4 categories: binding affinity to biological polymers, binding of heavy metal ions, catalyst of electron transport and ability to scavenge free radicals. ${ }^{18}$ This could also be related to propolis inhibitory effect on MMP9 due to presence of caffeic acid and phenyl ester. ${ }^{8}$ 
These results are in accordance with Perote et al, who stated that, propolis may be an alternative to chlorohexidine as an MMP inhibitor for dentin bonding as both solutions presented same results on his study (did not reduce bond strength compared to control). ${ }^{19}$. This results also agrees with Sodgar et al who found that, the bond strength with $1 \%$ nanopropolis and $2 \%$ nano propolis was above the acceptable clinical range ${ }^{10}$. This is also in agree with Yazici who stated that propolis had no adverse effect on bond strength when used before the adhesive as a cavity disinfectant. ${ }^{20}$

However, this result is in disagree with Luhrs et al. who found that MMP inhibitor could not prevent the decrease in microtensile bond strength upon aging and did not improve the durability of resin composite luting cement. ${ }^{21}$ This may be related to the difference in the adhesive type and the aging they made to the specimens.

Chitosan is a biopolymer obtained by alkaline deacetylation from chitin. ${ }^{22}$ Chitosan nanoparticles were suggested to improve the resistance of the dentin surface to degradation by collagenase. ${ }^{23}$ It can produce a microfibrillar and nanofibrillar network with excellent mechanical properties. When this network is associated with bonding agents, it has the potential to improve the mechanical properties of dentin. ${ }^{24}$

However, in this study nanochitozan group showed decreased $\mu$ TBS compared to nanopropolis group and there was no statistically significant difference from the control group. The decreased microtensile bond strength found in nanochitozan group could be explained by the obliteration of the interfibrillar spaces due to aggregation of the chitosan inside demineralized dentin collagen network. This obliteration of the interfibrillar spaces might cause poor resin infiltration with rough textured hybrid layer ${ }^{25}$ This result agrees with Elsaka et al who incorporated different concentrations of chito$\operatorname{zan}(0.12 \%, 0.25 \%, 0.5 \%$ and $1 \%)$ into conventional adhesives, and observed that the concentrations of
0.12 and $0.25 \%$ did not affect the bond strength values, but higher concentrations of $1 \%$ led to decrease in the values. ${ }^{26}$ This is also in agree with Diolosà et al. who observed that the immediate bond strength did not differ between the control and experimental groups with chitosan incorporated. ${ }^{27}$ This also in agreement with Zidan who found that, when the dentin was treated with chitosan solution for $60 \mathrm{~s}$, prior to application of the adhesive, no significant change has occurred in the 24 hours microtensile bond strength and nanoleakage values. ${ }^{28}$

To our knowledge, no study has been conducted in the literature that compared the microtensile bond strength after application of nanopropolis and nanochitozan. However, this study evaluated the effect of nanopropolis and nanochitozan on the immediate bond strength, and further investigations needed to investigate their effect on the bond strength after aging. Also, further studies needed to evaluate effect of different concentrations of nanopropolis and nanochitozan on the bond strength of different adhesives to dentin.

\section{CONCLUSION}

Within the limitations of this in vitro study, it could be concluded that, nanopropolis (conc 1\%) enhance the immediate $\mu$ TBS of Prime \& Bond ${ }^{\mathrm{TM}}$ universal adhesive to dentin. Nanochitozan (conc $1 \%$ ) did not improve the $\mu$ TBS of Prime \& Bond ${ }^{\mathrm{TM}}$ universal adhesive to dentin.

\section{REFERENCES}

1. Spencer P, Jonggu Park QY, Misra A, Bohaty BS, Singh V, Parthasarathy R, et al. Durable bonds at the adhesive/ dentin interface: an impossible mission or simply a moving target? Braz Dent Sci. 2012 Jan;15(1):4-18.

2. Matos AB, Trevelin LT, Silva BTFD, Francisconi-DosRios LF, Siriani LK, CardosoMV. Bonding efficiency and durability: current possibilities. Braz Oral Res. 2017Aug 28;31(suppl 1): e57.

3. Cheung RC, Ng TB, Wong JH, Chan WY. Chitosan: an update on potential biomedical and pharmaceutical applications. Mar Drugs. 2015 Aug14;13(8):5156-86. 
4. Pinto RJ, Fernandes SC, Freire CS, et al. Antibacterial activity of optically transparent nanocomposite films based on chitosan or its derivatives and silver nanoparticles. Carbohydr Res. 2011; 348: 77-83.

5. Friedman M, Juneja VK. Review of antimicrobial and antioxidative activities of chitosans in food. J Food Prot .2010; 73 (9): 1737-61.

6. Elsaka SE. Antibacterial activity and adhesive properties of a chitosan-containing dental adhesive. Quintessence Int. 2012;43(7):603-613

7. E. Ghisalberti, "Propolis: a review," BeeWorld. 1979; 60 (2): 59-84.

8. Jin UH, Chung TW, Kang SK, Suh SJ, Kim JK, Chung KH, Gu YH, Suzuki I, Kim CH. Caffeic acid phenyl ester in propolis is a strong inhibitor of matrix metalloproteinase-9 and invasion inhibitor: isolation and identification. Clin Chim Acta. 2005;362; 57-64.

9. Taylor R, Coulombe S, Otanicar T, Phelan P, Gunawan A, Lv W, et al. Small particles, big impacts: A review of the diverse applications of nanofluids. J Appl Phys. 2013. January;113(1):011301.

10. Higareda MC, Ramos-García MD, Pacheco ZN,Río-García JC, Bautista-Banos S. Nanostructured chitosan/propolis formulations: characterization and effect on the growth of Aspergillus flavus and production of aflatoxins. Heliyon.2019 May; e01776. (5): 1-7.

11. Sodagar A, Akhavan A, Arab S, Bahador A, Pourhajibagher M, and Soudi A.Evaluation of the Effect of Propolis Nanoparticles on Antimicrobial Properties and Shear Bond Strength of Orthodontic Composite Bonded to Bovine Enamel Front Dent .2019; 16(2): 96-104.

12. Montagner AF, Sarkis-Onofre R, Pereira-Cenci T, Cenci MS. MMP Inhibitors on dentin stability: a systematic review and meta-analysis. J Dent Res. 2014 Aug;93(8):733-43.

13. Banskota AH, Tezuka Y, Kadota S. Recent progress in pharmacological research of propolis. Phytother Res. 2001. November;15(7):561-71.

14. Grenho L, Barros J, Ferreira C, Santos VR, Monteiro FJ, Ferraz MP, et al. In vitro antimicrobial activity and biocompatibility of propolis containing nanohydroxyapatite. Biomed Mater. 2015. March 18;10(2):025004.

15. Yildirim Z, Oncul N, Yıldırım M. Chitosan and its antimicrobial properties. Omer Halisdemir University Journal of Engineering Sciences. 2016; 5:19-36.

16. Hayashi Y, Ohara N, Ganno T, et al. Chitosan-containing gum chewing accelerates antibacterial effect with an increase in salivary secretion. J Dent. 2007; 35:871-4.

17. Moreno MI, Isla MI, Sampietro AR, Vattuone MA. Comparison of the free radical-scavenging activity of propolis from several regions of Argentina. J Ethnopharmacol. 2000. July;71(1-2):109-14.

18. Perchyonok, V.T., Zhang, S.M. and Grobler, S.R. IPNs from Cyclodextrin: Chitosan Antioxidants: Bonding, Bioadhesion, Antioxidant Capacity and Drug Release. Journal of Functional Materials. 2014: 5: 183-196.

19. Perote LC, Kamozaki MP, Gutierrez NC, Tay FR, Pucci CR. Effect of matrix metalloproteinase- inhibiting solutions and aging methods on dentin bond strength. J Adhes Dent.2015; 17; 347-352.

20. Arslan S, Yazici AR, Gorucu J, Ertan A, Pala K, Ustün Y, Antonson SA, Antonson DE. Effects of different cavity disinfectants on shear bond strength of a Silorane-based Resin Composlte. The Journal of Contemporary Dental Practice, July-August 2011;12(4):279-286.

21. Luhrs AK, De Munck J, Geurtsen W, Van Merbeek B. Does inhibition of proteolytic activity improve adhesive lutting? Eur J Oral Sci.2013;121(2):121-131.

22. Del Carpio-Perochena A, Bramante CM, Duarte MA, de Moura MR, Aouada FA, Kishen A. Chelating and antibacterial properties of chitosan nanoparticles on dentin. Restor Dent Endod. 2015 Aug;40(3):195-201.

23. Kishen A, Shrestha S, Shrestha A, Cheng C, Goh C. Characterizing the collagen stabilizing effect of crosslinked chitosan nanoparticles against collagenase degradation. Dent Mater. 2016 Aug;32(8):968-77.

24. Lobato MF, Turssi CP, Amaral FL, França FM, Basting RT. Chitosan incorporated in a total-etch adhesive system: antimicrobial activity against Streptococcus mutans and Lactobacillus casei. Gen Dent. 2017 Jan-Feb;65(1):62-66.

25. Balaji H. MMP inhibitors-A review. Int J Pharm Sci Heal Care Issue.2017;2 (7):45-56.

26. Elsaka SE. Antibacterial activity and adhesive properties of a chitosan-containing dental adhesive. Quintessence Int. 2012 Jul-Aug;43(7):603-13.

27. Diolosà M, Donati I, Turco G, Cadenaro M, Di Lenarda $\mathrm{R}$, BreschiL, et al. Use of methacrylate-modified chitosan to increase the durability of dentine bonding systems. Biomacromolecules. 2014 Dec;8(12):4606-13.

28. Zidan A. Effect of chitosan on resin-dentin interface durability: a 2 year in-vitro study. E.D.J. 2019; 65(3): 2955:2965. 